\title{
pG2 gene expression and its regulation in human adrenocortical and medullary tumors
}

\author{
Jianqi Liu ${ }^{1,2}$, Raimo Voutilainen ${ }^{1,2}$, Päivi Heikkilä ${ }^{1}$ and Arvi I Kahri ${ }^{1}$ \\ ${ }^{1}$ Department of Pathology, PO Box 21, University of Helsinki, FIN-O0014 Helsinki, Finland and ${ }^{2}$ Department of Pediatrics, Kuopio University \\ Hospital, PO Box 1777, FIN-70210 Kuopio, Finland \\ (Correspondence should be addressed to J Liu, Department of Pathology, PO Box 21, University of Helsinki, FIN-OOO14 Helsinki, Finland)
}

\begin{abstract}
The cDNA clone pG2 was originally isolated from a human pheochromocytoma. The respective gene was found to be strongly expressed in normal adrenal zona glomerulosa and medulla, as well as in Conn's adenomas and pheochromocytomas. To shed more light on the expression and regulation of the pG2 gene, we investigated its expression in a wide variety of different adrenal neoplasms and cultured adrenal cells. Northern blot analysis was used to determine the steady state level of pG2 mRNA. Besides normal adrenals, Conn's adenomas and pheochromocytomas, we found abundant expression of pG2 mRNA in Cushing's, virilizing and nonfunctional adrenocortical adenomas and carcinomas, as well as in hyperplastic adrenals. The relative levels of pG2 mRNA in various adrenocortical tumors were not significantly different from those in normal adrenals and pheochromocytomas. In primary cultures of normal adrenal cells, treatment with adrenocorticotropin induced a 3- to 15 -fold increase in the expression of pG2 mRNA $(P<0.01)$, and this effect was reproduced by incubation with $(\mathrm{Bu})_{2} \mathrm{cAMP}$. In cultured pheochromocytoma cells, treatment with $(\mathrm{Bu})_{2} \mathrm{cAMP}$ and a protein kinase inhibitor, staurosporine, increased pG2 mRNA accumulation (2- to 4-fold over the control level, $P<0.01$, and 3 - to 8 -fold, $P<0.01$, respectively). These results indicate that pG2 is widely expressed in normal and pathological adrenal tissues from both cortical and medullary origin, which eliminates its usefulness as a specific marker for zona glomerulosa or medullary adrenal tumors. Accumulation of pG2 mRNA is regulated by multiple differentiating factors through different pathways in primary cultures of normal adrenal and pheochromocytoma cells.
\end{abstract}

European Journal of Endocrinology 140 590-596

\section{Introduction}

The cDNA clone pG2 was originally isolated on the basis of its differential expression in a human pheochromocytoma, a tumor of mature adrenal chromaffin cells, versus a neuroblastoma. Expression of pG2 mRNA was demonstrated to be limited uniquely to the normal adult adrenal gland, including both adrenal cortex and medulla. Therefore, pG2 was supposed to be adrenal specific (1). Nucleic and amino acid sequence alignments revealed that pG2 is a homolog to a number of recently published cDNAs. These homologous genes are expressed in various tissues and show different functions. Preadipocyte factor-1 (Pref-1) may be involved in the differentiation of 3T3-L1 fibroblasts to adipocytes (2). A putative homeotic Delta-like protein (dlk) is expressed in tumors with neuroendocrine features (3). Mouse stromal cell-derived protein 1 (SCP-1) was cloned originally from a stromal cell line PA6 (4). Rat adrenal zona glomerulosa-specific factor (ZOG) is specifically expressed in cells forming several layers just beneath the adrenal capsule $(5,6)$.
Fetal antigen-1 (FA-1) was originally isolated from second trimester amniotic fluid (7), and it is most likely the secreted form of the protein translated from the above mentioned mRNAs (8). These mRNAs may be transcribed from the same gene as splice variants in different tissues, and post-translational tissue-specific modifications may exist (8-10). Immunohistochemical studies have demonstrated these proteins in fetal adrenals, hepatocytes, all glandular cells of the early pancreas primordium, and around the blood islands of the yolk sac $(8,11)$. In adult tissues, these mRNAs have been detected in placenta, insulin producing $\beta$-cells, somatotropic cells of the pituitary gland, and a number of neuroendocrine tumors, while the most pronounced expression was seen in the adrenals $(1,3,8)$.

The role of strong pG2 mRNA expression in adrenals is still obscure. The highly restricted tissue distribution of pG2 mRNA expression suggests that pG2 may play an essential role in the differentiation and/or proliferation process of adrenal cells. In the adult adrenal gland pG2 was found to be highly expressed in both cortical and medullary tissues (1). Immunohistochemical studies 
revealed a strong staining reaction in the zona glomerulosa of the cortex $(6,12)$. Consistently, human Conn's adenomas also contained abundant pG2 mRNA, in contrast to the absence of pG2 mRNA in mouse adrenal zona fasciculata-derived Y-1 cells (5). In human adrenal medulla, pG2 mRNA has been shown to be a midgestational marker of the chromaffin cell lineage and it was found to increase 4 weeks after the appearance of tyrosine hydroxylase; it was the first identified marker of chromaffin development (13). However, although pG2 was originally cloned from human adrenal tissues, its expression pattern in different adrenal tumors and hyperplasias has not been investigated systematically. In the present study, we analyzed the expression of pG2 mRNA in a variety of pathological adrenal tissues, and further investigated its regulation in cultured normal adrenal and pheochromocytoma cells.

\section{Materials and methods}

\section{Patients}

Normal adrenals were obtained from patients who underwent nephrectomy for kidney tumors. Pathological adrenal glands were obtained during the operations performed at the Department of Surgery, Helsinki University Central Hospital. The pathological adrenal tissues investigated in this study included bilateral and nodular adrenocortical hyperplasias, Cushing's, Conn's, virilizing and nonfunctional (on the basis of clinical data) adrenocortical adenomas and carcinomas, as well

Table 1 Relative levels of pG2 mRNA in normal and pathological adrenal tissues.

\begin{tabular}{lrc}
\hline Tissue & $\boldsymbol{n}$ & $\begin{array}{c}\text { pG2 } \\
\text { (mean (range)) }\end{array}$ \\
\hline Normal adrenal & 14 & $100(66-130)$ \\
Adrenocortical adenoma (Cushing's) & 8 & $122(41-285)$ \\
$\quad$ Adjacent gland & 5 & $107(32-276)$ \\
Adrenocortical adenoma (Conn's) & 9 & $93(28-218)$ \\
Adjacent gland & 7 & $103(49-193)$ \\
Adrenocortical adenoma (virilizing) & 3 & $163(71-223)$ \\
Adjacent gland & 1 & 108 \\
Adrenocortical adenoma (nonfunctional) & 3 & $112(89-128)$ \\
Adjacent gland & 3 & $133(119-149)$ \\
Adrenocortical hyperplasia (bilateral) & 10 & $122(18-228)$ \\
Adrenocortical hyperplasia (nodular) & 5 & $126(53-285)$ \\
Adjacent gland & 3 & $106(102-113)$ \\
Adrenocortical carcinoma & 5 & $64(17-129)$ \\
Pheochromocytomas & 17 & $313(52-620)$ \\
Adjacent gland & 7 & $89(23-219)$ \\
\hline
\end{tabular}

The values were calculated from scanned autoradiographic signals of Northern blots. Most RNA samples were blotted more than twice and the data are the average values. All values were normalized with the respective $28 \mathrm{~S}$ ribosomal RNA signals. Means and ranges (in parentheses) are shown. The means of the RNA values from normal adrenals were artificially adjusted to 100 . as pheochromocytomas (Table 1). All tissue specimens were sent to the Department of Pathology, where they were dissected within half an hour, and the diagnosis was established based on the combination of clinical and histological parameters. The procedures followed were in accordance with the principles of the Local Ethical Committee.

\section{Cell cultures}

Small pieces of the adrenal tissues were briefly frozen in liquid nitrogen and then stored at $-70{ }^{\circ} \mathrm{C}$. The remaining tissues from normal adrenal glands and pheochromocytomas were cultured as described previously (14). The growth and morphological characteristics of the cultured cells were assessed by phase contrast light microscopy. The experiments were performed in triplicate wells. Synthetic adrenocorticotropin 1-24 (ACTH) was obtained from N V Organon (Oss, Holland). (Bu) $)_{2} \mathrm{cAMP}$, 12-O-tetradecanoyl phorbol 13-acetate (TPA), staurosporine, and 7S-nerve growth factor (NGF) were purchased from Sigma (St Louis, MO, USA).

\section{RNA analysis}

Total RNA was isolated from the frozen tissues by ultracentrifugation through a cesium chloride cushion (15). Extraction of cytoplasmic RNA, Northern blotting, and hybridizations were performed as previously described $(14,16)$. A 30-mer oligonucleotide probe for pG2 mRNA was synthesized at the Institute of Biotechnology, University of Helsinki. The sequence was 5'-TTG AGC TCT TTC ATG GAC ACC TTC AGG ATG -3', corresponding to the nucleotides 1011-1040 of the human pG2 cDNA (GenBank accession no. X17544) (17). This sequence is also complementary to the corresponding nucleotides of human dlk (GenBank accession no. U15979), rat Pref-1 (GenBank accession no. U25680) and mouse SCP-1 (GenBank accession no. D16847) mRNAs. For molecular verification of Conn's adenomas, an oligonucleotide probe for P450c18 (steroid 18-hydroxylase) was used. Its sequence was 5'-ATG CAA GAC TAG TTA ATC GCT CTG AAA GTG-3', corresponding to the nucleotides 6445-6474 of the human P450c18 gene (GenBank accession no. D13752) (18). Ribosomal 28S RNA was used as a loading control (19). The oligonucleotide and cDNA probes were labeled as described previously (20). The relative intensities of autoradiographic signals were quantitated by densitometric scanning. All the data shown here were normalized with the respective 28S RNA values. The correlations of different mRNA concentrations in the in vivo adrenal samples were analyzed by Spearman's test. Differences in the mean mRNA levels were assessed by the MannWhitney test. The level of significance was chosen as $P<0.05$. 


\section{Results}

Consistent expression of pG2 mRNA was detected in all adrenal tissues investigated (Fig. 1). Northern blot analysis revealed a major mRNA species of approximately $1.7 \mathrm{~kb}$ in normal and pathological adrenals in vivo and in vitro. In addition, a much less abundant transcript of approximately $4 \mathrm{~kb}$ in size was detected in some pheochromocytoma samples in vivo (Fig. 1A), as reported previously in rat adrenals (10). In agreement with previous reports $(1,5)$, normal adrenals, Conn's adenomas and pheochromocytomas abundantly expressed pG2 mRNA (Fig. 1A,B). The relative level of pG2 mRNA in 9 Conn's adenomas and 17 pheochromocytomas was not significantly different from those in normal or the tumor adjacent adrenals (all $P>0.05$ ). P450c18 mRNA expression was used as a molecular marker for Conn's adenomas, where it was readily detected (Fig. 1B) as reported previously (18). Expression of P450c18 mRNA was undetectable in normal adrenals and other pathological adrenocortical tissues in our Northern blots exposed for up to 28 days. In addition, Cushing's, virilizing and nonfunctional adrenocortical adenomas, bilateral and nodular adrenocortical hyperplasias and adrenocortical carcinomas (Cushing's, aldosterone-secreting, virilizing and nonfunctional type) expressed pG2 mRNA to the same extent (Fig. 1C and Table 1). Expression of pG2 mRNA was also detected in human ovarian granulosa cells (from in vitro fertilization patients), a human Leydig cell tumor and rat pheochromocytoma PC12 cells, with the same transcript size as in human adrenals. In contrast, there was no detectable expression of pG2 mRNA in liver and parathyroid adenomas (data not shown).

In cultured normal adrenal cells, treatment with ACTH increased pG2 mRNA accumulation in a doseand time-dependent manner. The induction of pG2 mRNA expression by ACTH was already detectable at a concentration of $0.3 \mathrm{nmol} / \mathrm{l}$ after $24 \mathrm{~h}$ of treatment, and the maximal increase (3- to 15-fold over the control level, $P<0.01$, in repeated experiments from six different adrenals) was reached with an ACTH concentration of $3 \mathrm{nmol} / \mathrm{l}$ upwards (Fig. 2A). Time-course experiments demonstrated a $50 \%$ increase in pG2 mRNA after $4 \mathrm{~h}$ of ACTH treatment, but the major induction occurred after $12 \mathrm{~h}$ incubation. $(\mathrm{Bu})_{2} \mathrm{cAMP}$ also enhanced pG2 mRNA expression dose-dependently (up to 7-fold, $P<0.01$, in repeated experiments from five adrenals), with maximal stimulation at a concentration of $1 \mathrm{mmol} / \mathrm{l}$. ACTH and $(\mathrm{Bu})_{2} \mathrm{cAMP}$ had no additive effect on pG2 mRNA accumulation (data not shown). As expected, both ACTH and $(\mathrm{Bu})_{2} \mathrm{cAMP}$ enhanced expression of the steroidogenic enzyme genes and secretion of cortisol from the cultured adrenal cells (data not shown) as reported previously (20). The effects of TPA $(160 \mathrm{nmol} / \mathrm{l})$ and staurosporine $(100 \mathrm{nmol} / \mathrm{l})$ on the basal or ACTH-induced expression of pG2 mRNA were variable, with slightly increased pG2 mRNA levels in some cultures but not in others (Fig. 2B). Statistical analysis showed that the effects of TPA and staurosporine were not significant (both $P>0.05$ ). We also detected high levels of pG2 expression in cultured Cushing's, Conn's and nonfunctional adrenocortical adenoma cells (data not shown).

In primary cultures of pheochromocytoma cells, treatment with staurosporine increased pG2 mRNA accumulation in a dose-dependent manner after 1 and 3 days of treatment. The induction of pG2 mRNA expression by staurosporine was already detectable at a concentration of $10 \mathrm{nmol} / \mathrm{l}$ after 3 days of treatment, and the maximal increase (3- to 8-fold over the control level, $P<0.01$, in repeated experiments from four different pheochromocytomas) was reached at $100 \mathrm{nmol} / \mathrm{l}$ (Fig. 3A,B). (Bu) ${ }_{2} \mathrm{cAMP}$ also enhanced pG2 mRNA expression at a concentration of $1 \mathrm{mmol} / \mathrm{l}$ after 3 days of treatment (2- to 4 -fold over the control level, $P<0.01$, in repeated experiments from three pheochromocytomas) (Fig. 3C). There was no significant difference between the levels of pG2 expression with $(\mathrm{Bu})_{2} \mathrm{cAMP} /$ staurosporine and that of $(\mathrm{Bu})_{2} \mathrm{cAMP}$ alone or staurosporine alone in repeated experiments. Changes in pG2 mRNA abundance in response to TPA $(160 \mathrm{nmol} / \mathrm{l})$ (Fig. 3C) were not statistically significant. NGF $(200 \mu \mathrm{g} / \mathrm{l})$ had no significant effect on pG2 mRNA expression (data not shown).

\section{Discussion}

It has previously been demonstrated that alternate splicing generates multiple forms of pG2 transcripts. Detection of the approximately $1.7 \mathrm{~kb}$ species of pG2 transcript in all our samples with Northern blot analysis indicates that it is the predominant form of pG2 mRNA in both normal and pathological adrenal tissues. This is in accordance with previous reports $(1,21)$. pG2 has been found to be specifically expressed in zona glomerulosa and medulla of normal adrenals, as well as in Conn's adenomas and pheochromocytomas $(1,5)$. Therefore, it is a potential marker for these tumors. We observed that pG2 is expressed not only in aldosterone-producing cells, but also in cortisol- and androgen-producing adrenocortical cells. The relative pG2 expression in Conn's adenomas and pheochromocytomas was not significantly different from that in normal adrenals and other adrenocortical tumors. The strong pG2 gene expression in glucocorticoid- and androgen-producing neoplasms is unlikely to originate from zona glomerulosa or chromaffin cells, since the zona glomerulosa specific marker P450c18 (this study) and the neuroectodermal marker chromogranin A (22) mRNAs were undetectable in these adrenocortical tumors. In fetal adrenals pG2 is expressed abundantly in nearly all adrenocortical cells. In contrast, expression of pG2 is located to the outer region of the neonatal adrenal cortex, and eventually restricted to 
A

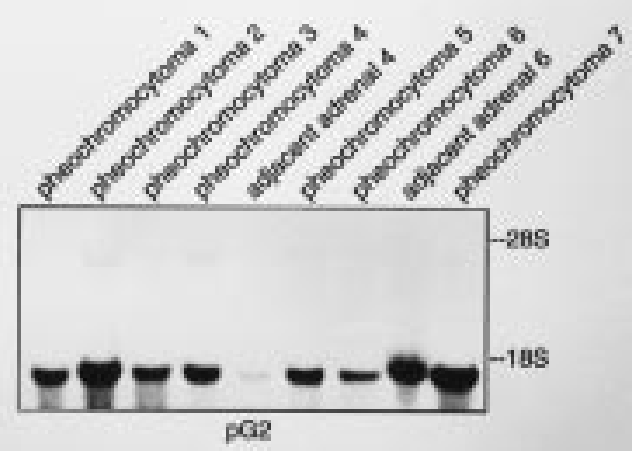

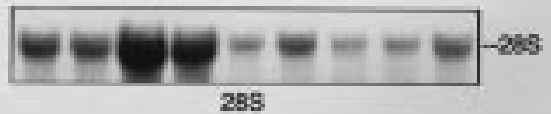

B

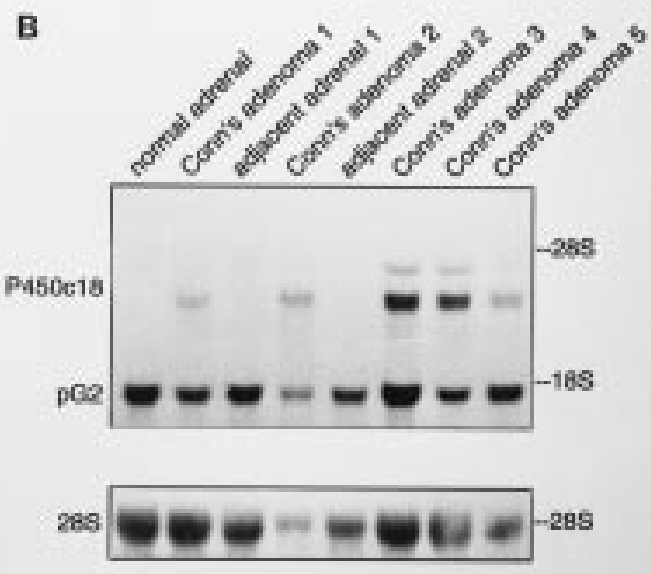

C

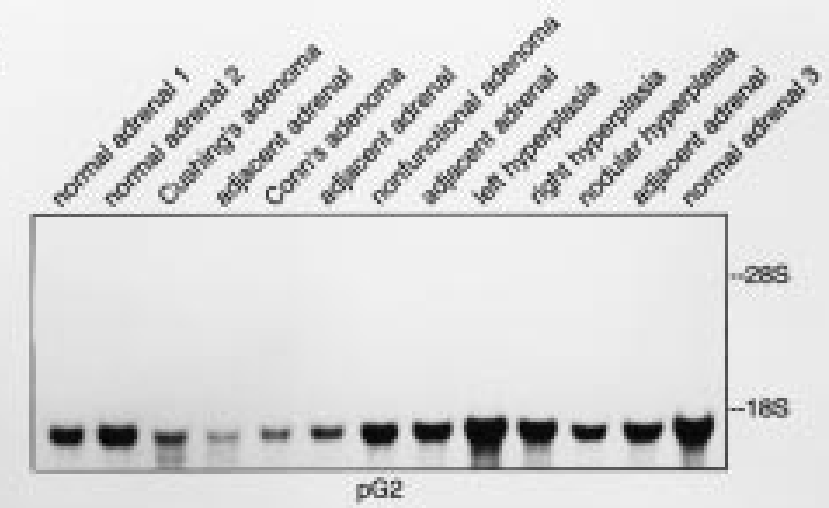

w
Figure 1 Expression of pG2 mRNA in (A)

pheochromocytomas, (B and C) Conn's, Cushing's, and nonfunctional adrenocortical adenomas, adrenocortical hyperplasias, normal adrenals and the tumor adjacent adrenal glands in vivo. Total RNA was extracted from the frozen tissues indicated. The Northern blots were prepared with $20 \mu \mathrm{g}$ total RNA in each lane, and the RNA was transferred onto nylon membranes. The filters were sequentially hybridized with ${ }^{32} \mathrm{P}$-labeled pG2, P450c18 (for those shown in B) and $28 \mathrm{~S}$ ribosomal RNA (as loading control) probes. The $\mathrm{P} 450 \mathrm{c} 18$ probe was used as a molecular marker for Conn's adenomas (B). The migration of $28 \mathrm{~S}$ and $18 \mathrm{~S}$ ribosomal RNAs is indicated. 

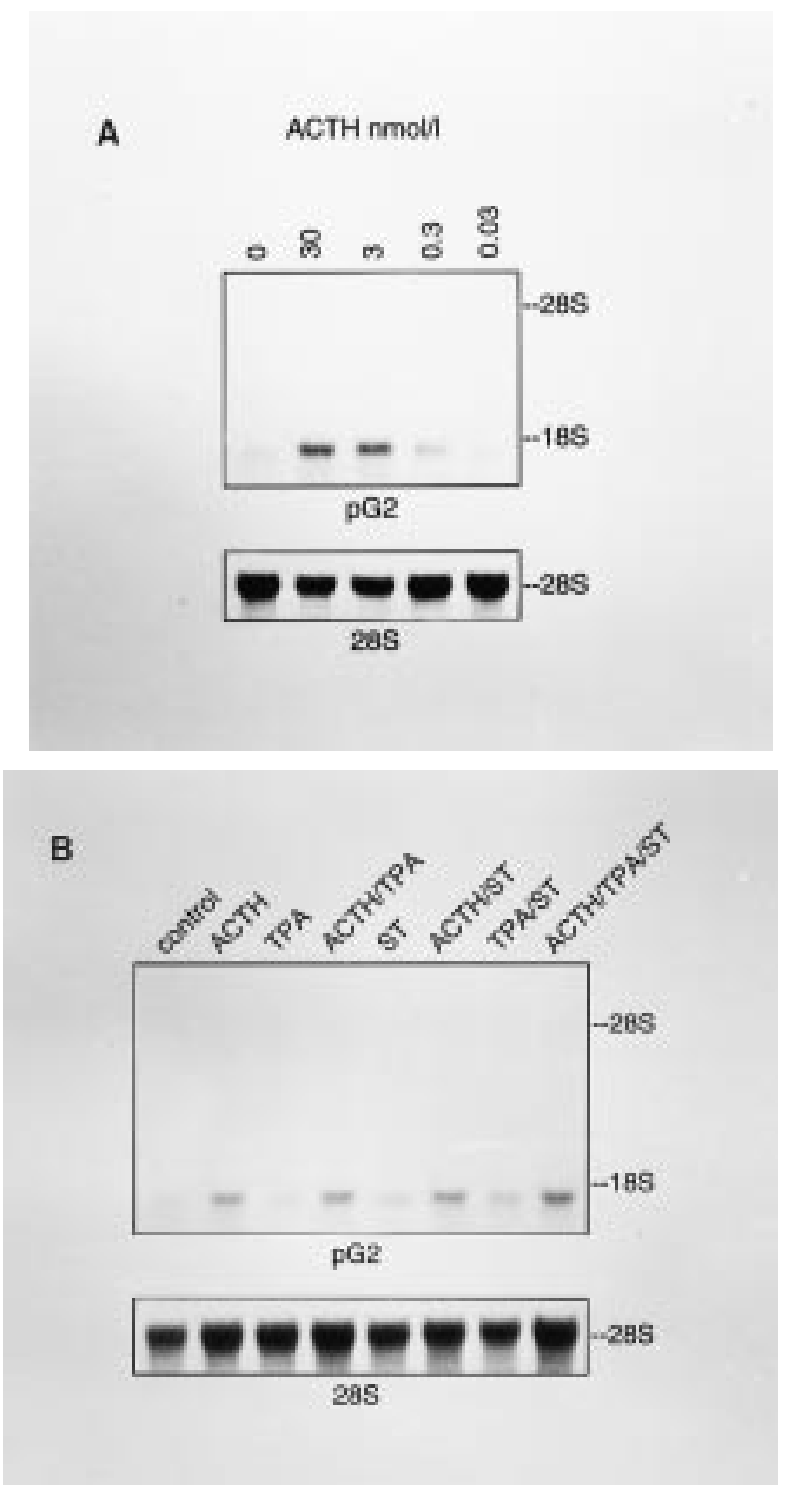

Figure 2 Regulation of pG2 mRNA accumulation in primary cultures of normal adrenal cells. The dispersed cells were allowed to grow for 5 days before the agents were added for $24 \mathrm{~h}$ of treatment. Cytoplasmic RNA was extracted and the Northern blots were prepared with $10 \mu \mathrm{g}$ RNA in each lane. The hybridization conditions were the same as for Fig. 1. (A) Dose-dependent effects of ACTH on the expression of pG2 mRNA. (B) Effects of ACTH $(30 \mathrm{nmol} / \mathrm{l})$, TPA $(160 \mathrm{nmol} / \mathrm{l})$ and staurosporine (ST; $100 \mathrm{nmol} / \mathrm{l})$ alone or in combination on the expression of pG2 mRNA. The experiments were repeated at least six times with cells from different patients, and the results were comparable.

the glomerulosa layer of adult adrenals, with minimal expression in the cells of fasciculata and reticularis layers $(5,12,13)$. In this respect, Cushing's, virilizing and nonfunctional adrenocortical tumors behaved unexpectedly with relatively abundant pG2 expression in these neoplasms. pG2 expression may somehow be related to steroidogenesis, as evidenced by its regulation in adrenocortical cells by a physiological hormone, ACTH, as well as its expression in ovarian granulosa cells and a Leydig cell tumor.

In primary cultures of normal adrenocortical cells, the accumulation of pG2 mRNA was up-regulated by ACTH, suggesting that ACTH may be at least one of the principal regulators of $\mathrm{pG} 2$ expression in adrenal cells. It is well known that actions of ACTH are mainly mediated through the activation of adenylate cyclase and the subsequent increase in intracellular cAMP. In our study, the stimulatory effect of ACTH was mimicked by $(\mathrm{Bu})_{2} \mathrm{cAMP}$ treatment, suggesting cAMPdependent protein kinase as the second messenger of ACTH action on pG2 expression. This appeared to be contrary to previous reports showing that there was no remarkable change in pG2 mRNA expression in the adrenal glands of ACTH-treated rats $(5,6)$. However, P450scc (cholesterol side-chain cleavage enzyme) mRNA was also unresponsive to ACTH in those reports, suggesting that the adrenocortical ACTH response may not have been optimal. Alternatively, the different response of pG2 gene expression to ACTH in rat and human may represent species specific differences.

It appeared that regulation of pG 2 mRNA expression may be tissue specific, because accumulation of pG2 mRNA was increased by a protein kinase inhibitor, staurosporine, in cultured pheochromocytoma cells but not in cultured adrenocortical cells. The effect of staurosporine in cultured pheochromocytoma cells may not be through the inhibition of protein kinase $A$ and $C$, since activation of the protein kinase $A$ pathway (by $(\mathrm{Bu})_{2} \mathrm{cAMP}$ treatment) also increased pG2 mRNA expression, and depletion of protein kinase $C$ by prolonged TPA incubation had no significant effect on pG2 gene expression. Staurosporine can elicit neurite outgrowth in pheochromocytoma cells in the absence of NGF receptors, suggesting staurosporine as a unique neurotropic compound (23). In our experiments, the increment of pG2 mRNA accumulation by staurosporine was accompanied with an increase in the expression of neuropeptide $\mathrm{Y}$ gene (J Liu, R Voutilainen, P Heikkilä \& A I Kahri, unpublished observation). Therefore, pG2 may not be a reliable chromaffin marker in pheochromocytoma tissues as suggested in previous reports $(1,13)$. Our data in pheochromocytoma cells are in agreement with $(\mathrm{Bu})_{2} \mathrm{cAMP}$ increasing expression of pG2 gene in a human neuroblastoma cell line SMS-KCNR (24).

Our data indicate that pG2 is widely expressed in normal and pathological adrenal tissues from both cortical and medullary origin. pG2 expression is not a useful marker for distinguishing different adrenal tumors. Expression of pG2 mRNA is responsive to multiple differentiating factors in primary cultures of normal adrenocortical and pheochromocytoma cells. 


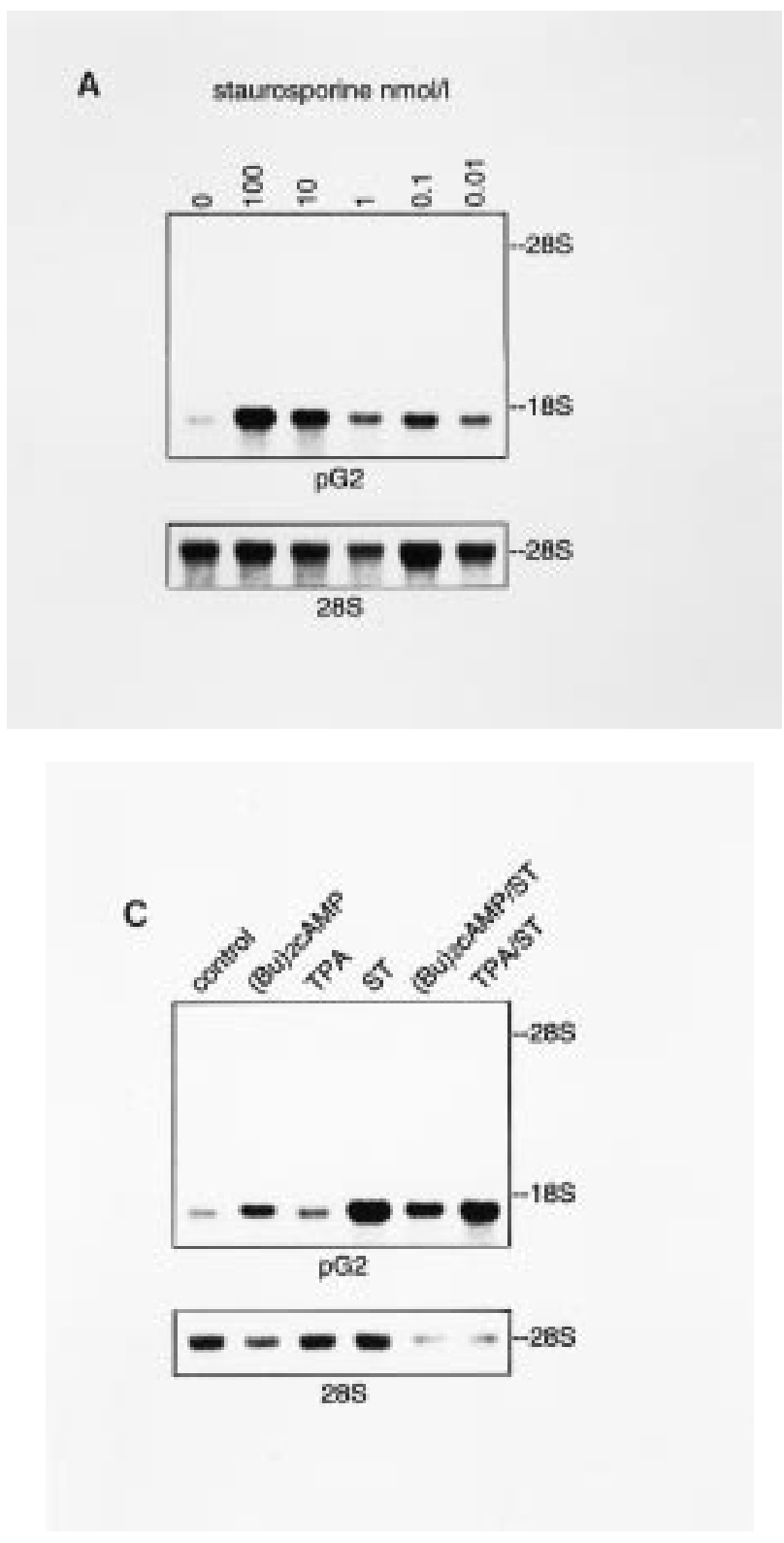

\section{Acknowledgements}

Ms Merja Haukka and Ms Eija Heiliö are thanked for their technical assistance. This study was financially supported by the Cancer Society of Finland, the Culture Foundation of Finland, the Jalmari and Rauha Ahokas Foundation (to JL), and Kuopio University Hospital Research Contract (5107) (to RV).

\section{References}

1 Helman LJ, Thiele CJ, Linehan WM, Nelkin BD, Baylin SB \& Israel MA. Molecular markers of neuroendocrine development and evidence of environmental regulation. Proceedings of the National Academy of Sciences of the USA $1987842336-2339$.

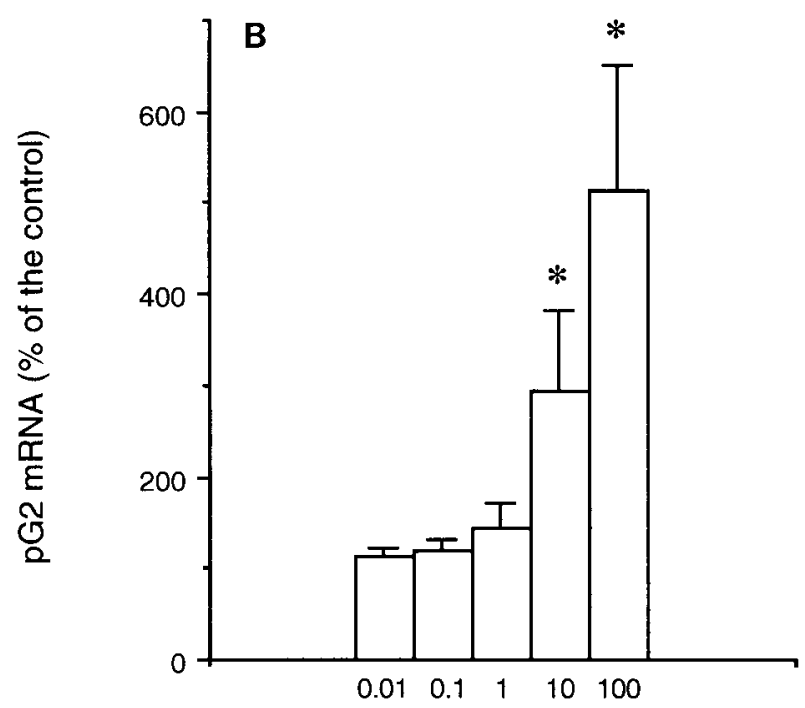

staurosporine $\mathrm{nmol} / \mathrm{l}$

Figure 3 Regulation of $p G 2$ mRNA expression in primary cultures of pheochromocytoma cells. After 7 days of culture, the cells were treated with staurosporine (ST; at the concentrations indicated in $\mathrm{A}$ and $\mathrm{B}$ or $100 \mathrm{nmol} / \mathrm{l}$ in $\mathrm{C}),(\mathrm{Bu})_{2} \mathrm{cAMP}(1 \mathrm{mmol} / \mathrm{l})$ and TPA $(160 \mathrm{nmol} / \mathrm{l})$ for 3 days. RNA analysis and hybridizations were the same as in Fig. 2. The experiments were repeated four times with cells from different patients, and the results were similar except for some variations in TPA-treated cells. The values in (B) represent means \pm S.E.M. of pooled data from four experiments, with the control level (without staurosporine treatment) adjusted to $100 .{ }^{*} P<0.05$ compared with the control.

2 Smas CM \& Sul HS. Pref-1, a protein containing EGF-like repeats, inhibits adipocyte differentiation. Cell 199373 725-734.

3 Laborda J, Sausville EA, Hoffman T \& Notario V. dlk, a putative mammalian homeotic gene differentially expressed in small cell lung carcinoma and neuroendocrine tumor cell line. Journal of Biological Chemistry 1993268 3817-3820.

4 Maruyama K, Nishijima S, Kuromitsu S. Ichikawa A, Masuda E, Takemoto T et al. Differential cloning of a gene encoding SCP-1, a transmembrane protein containing EGF-like repeats from mouse stromal cell line PA6. GenBank Seq 1993, NID:g391760.

5 Okamoto M, Takemori H, Halder SK \& Hatano O. Zona glomerulosa-specific factor: cloning and function. Steroids 1997 62 73-76.

6 Halder SK, Takemori H, Hatano O, Nonaka Y, Wada A \& Okamoto M. Cloning of a membrane-spanning protein with epidermal growth factor-like repeat motifs from adrenal glomerulosa cells. Endocrinology $19981393316-3328$. 
7 Fay TN, Jacobs I, Teisner B, Poulsen O, Chapman MG, Stabile I et al. Two fetal antigens (FA-1 and FA-2) and endometrial proteins (PP12 and PP14) isolated from amniotic fluid; preliminary observations in fetal and maternal tissues. European Journal of Obstetrics and Gynecology and Reproductive Biology 198829 73-85.

8 Jensen CH, Krogh TN, Hojrup P, Clausen PP, Skjodt K, Larsson LI et al. Protein structure of fetal antigen 1 (FA1): a novel circulating human epidermal growth factor-like protein expressed in neuroendocrine tumors and its relation to the gene products of dlk and pG2. European Journal of Biochemistry $199422583-$ 92.

9 Smas CM \& Sul HS. Characterization of Pref-1 and its inhibitory role in adipocyte differentiation. International Journal of Obesity 199620 (Suppl 3) S65-S72.

10 Carlsson C, Tornehave D, Lindberg K, Galante P, Billestrup N, Michelsen B et al. Growth hormone and prolactin stimulate the expression of rat preadipocyte factor- $1 / \Delta$-like protein in pancreatic islets: molecular cloning and expression pattern during development and growth of the endocrine pancreas. Endocrinology 1997138 3940-3948.

11 Tornehave D, Fay TN, Teisner B, Chemnitz J, Westergaard JG \& Grudzinskas JG. Two fetal antigens (FA-1 and FA-2) and endometrial proteins (PP12 and PP14) isolated from amniotic fluid: localisation in the fetus and adult female genital tract. European Journal of Obstetrics and Gynecology and Reproductive Biology 198930 221-232.

12 Jensen CH, Teisner B, Hojrup P, Rasmussen HB, Madsen OD, Nielsen B et al. Studies on the isolation, structural analysis and tissue localization of fetal antigen 1 and its relation to human adrenal-specific cDNA, pG2. Human Reproduction 19938 635-641.

13 Cooper MJ, Hutchins GM, Cohen PS, Helman LJ, Mennie RJ \& Israel MA. Human neuroblastoma tumor cell lines correspond to the arrested differentiation of chromaffin adrenal medullary neuroblasts. Cell Growth and Differentiation 19901 149-159.

14 Liu J, Kahri AI, Heikkilä P, Ilvesmäki V \& Voutilainen R. H19 and insulin-like growth factor-II gene expression in adrenal tumors and cultured adrenal cells. Journal of Clinical Endocrinology and Metabolism $199580492-496$.
15 Chirgwin JM, Przybyla AE, MacDonald RJ \& Rutter WJ. Isolation of biologically active ribonucleic acid from sources enriched in ribonuclease. Biochemistry 197918 5294-5299.

16 Voutilainen R, Tapanainen J, Chung B, Matteson KJ \& Miller WL. Hormonal regulation of P450scc (20,22-desmolase) and P450c17 (17 $\alpha$-hydroxylase/17,20-lyase) in cultured human granulosa cells. Journal of Clinical Endocrinology and Metabolism $198663202-207$.

17 Helman LJ, Sack N, Plon SE \& Israel MA. The sequence of an adrenal specific human cDNA, pG2. Nucleic Acids Research 1990 18685.

18 Kawamoto T, Mitsuuchi Y, Ohnishi T, Ichikawa Y, Yokoyama Y, Sumimoto $\mathrm{H}$ et al. Cloning and expression of a cDNA for human cytochrome P-450aldo as related to primary aldosteronism. Biochemical and Biophysical Research Communications 1990173 309-316.

19 Arnheim N. Characterization of mouse ribosomal gene fragments purified by molecular cloning. Gene $1979783-96$.

20 Liu J, Heikkilä P, Kahri AI \& Voutilainen R. Expression of the steroidogenic acute regulatory protein mRNA in adrenal tumors and cultured adrenal cells. Journal of Endocrinology 1996150 43-50.

21 Smas CM, Green D \& Sul HS. Structural characterization and alternate splicing of the gene encoding the preadipocyte EGF-like protein Pref-1. Biochemistry 199433 9257-9265.

22 Liu J, Voutilainen R, Kahri AI \& Heikkilä P. Expression patterns of the c-myc gene in adrenocortical tumors and pheochromocytomas. Journal of Endocrinology 1997152 175-181.

23 Rasouly D, Shavit D, Zuniga R, Elejalde RB, Unsworth BR, Yajon A et al. Staurosporine induces neurite outgrowth in neuronal hybrids (PC12EN) lacking NGF receptors. Journal of Cellular Biochemistry 199662 356-371.

24 Gaetano C, Matsumoto K \& Thiele CJ. In vitro activation of distinct molecular and cellular phenotypes after induction of differentiation in human neuroblastoma cell line. Cancer Research 1992 $524402-4407$.

Received 11 November 1998

Accepted 17 February 1999 